\title{
Voyage autour
}

du monde dans le

regard de l'autre

L'homme pluriel

Photos de Patrick De Wilde,

Textes d'Axel Khan

\section{Hervé Chneiweiss}

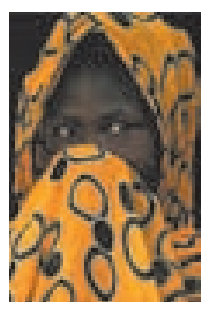

Plasticité gliale, UMR-S 752 Inserm/Paris Descartes/CHSA, Centre Paul Broca, 2ter rue d'Alésia, 75014 Paris, France. Herve.Chneiweiss@inserm.fr
C'est un très beau livre, grand format, portraits sur fond noir, édition soignée [1], un tour du monde en 60 visages, 60 regards, comme celui de cet adolescent namibien à qui Axel Kahn prête sa voix: «Regardez-moi, voyez comme je suis beau mais fragile, au loin mais des vôtres. Nous habitons une même Terre, aucun de nous ne se sauvera seul. Nous sommes solidaires... ». Patrick de Wilde a choisi le portrait, avec toujours le même appareil, un Nikon F5, le même objectif, $105 \mathrm{~mm}$ de focale 1,8, la même pellicule (et oui, des clichés sur pellicule!) Fuji Velvia de 50 ASA, et nous garantit qu'il n'a pas retouché les clichés. C'est toujours systématiquement le même fond noir transporté sous forme de studio aux quatre coins du monde,

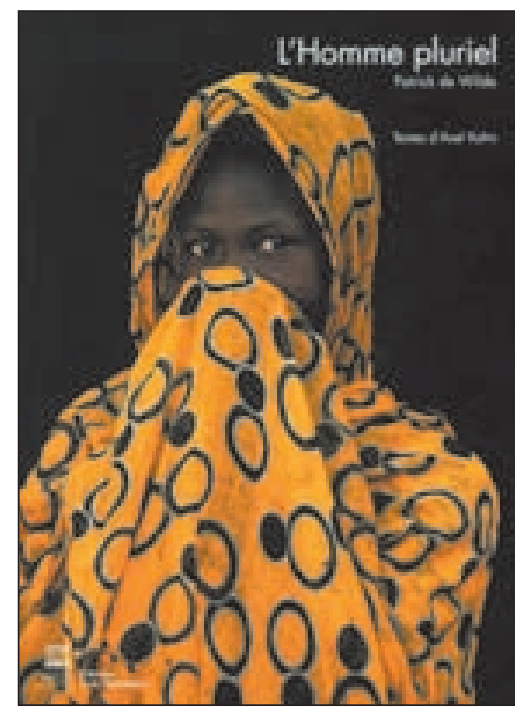

Face à ces images, Axel Kahn laisse résonner la voix intérieure et tisse au fil des pages des dialogues vibrant de sensibilité.

L'Unesco en fit une exposition et Vuibert maintenant un livre. L'homme pluriel en 60 regards représente à l'évidence et par nécessité un choix arbitraire. Aucun Européen par exemple. Hasard des voyages ou invitation à une suite sans doute. Un très beau cadeau à un prix très raisonnable $(29 €)$.

Donc obligatoire en décembre pour les cadeaux. $\diamond$

The plural man

\section{RÉFÉRENCE}

1. Kahn A, De Wilde P. L'homme pluriel. Paris : Éditions De La Martinière, 2008.

Asie, Afrique, Amériques, les jungles, les montagnes ou les déserts, des enfants, des femmes et des hommes de tous âges, pour retraduire avec les moyens de la photo le principe du portrait d'atelier flamand à la Van Eyck ou à la Rembrandt. II y a des regards de malice, certains de tristesse et d'inquiétude aussi. II y a des visages lisses ouverts à la vie et des faces ridées qui disent la dureté des temps.

H. Chneiweiss 